\section{Antagonism of Hypotensive Action of Bethanidine by "Common Cold" Remedy}

British Medical fournal, 1970, 4, 347

Various drugs are known to antagonize the actions of bethanidine and related compounds (see below). The following case report shows the probable antagonism of the hypotensive action of bethanidinet by a commonly used "cold" remedy, Ornade (phenylpropanolamine hydrochloride $50 \mathrm{mg}$., chlorpheniramine maleate $8 \mathrm{mg}$., isopropamide $2.5 \mathrm{mg}$ ).

\section{CASE REPORT}

A 46-year-old Negro housewife was admitted to the Presbyterian University Hospital on 25 January, 1968, complaining of anorexia, persistent headache, and epistaxis. She had been hypertensive for at least four years and had been treated with a variety of hypotensive agents. On physical examination she appeared chronically ill, with a blood pressure of $220 / 140 \mathrm{~mm}$. Hg. Funduscopic examination revealed an arteriovenous ratio of $1: 3$, with peripheral arteriovenous "nicking," bilateral papilloedema, and numerous flame haemorrhages and soft exudates. The heart was enlarged and a left ventricular diastolic gallop was heard. The rest of the physical examination including a complete neurological examination was within normal limits.

The urine analysis showed two-plus proteinuria and a normal sediment. The blood urea nitrogen was $75 \mathrm{mg} . / 100 \mathrm{ml}$. and the serum creatinine $13.5 \mathrm{mg} . / 100 \mathrm{ml}$. Tests for secondary forms of hypertension were negative and included a normal 24-hour excretion of urinary catecholamines.

The effect of her admission to hospital alone on the blood pressure is shown for days 1 to 3 in the Chart. Beginning on day 3 bethanidine sulphate $20 \mathrm{mg}$. by mouth daily was given in divided doses, satisfactory blood pressure control being obtained on days 4 to 11 , with regression of the papilloedema. On the evening of day 11 the patient complained of a cold with mild rhinitis and was given one Spansule of Ornade. On day 12 the dosage of Ornade was repeated twice at an interval of 12 hours. The blood pressure rose soon after the first dose and remained at high levels until day 16. Papilloedema recurred and severe headache with mental confusion supervened late on day 15 .

Intravenous diazoxide $\ddagger$ ( $300 \mathrm{mg}$.) on days 15 and 16 produced a less-than-usual response, and trimetaphan camsylate intravenously ( 8 and $16 \mathrm{mg} . / \mathrm{min}$.) was without effect on the blood pres sure. Intravenous phentolamine hydrochloride $(5 \mathrm{mg}$.), however, repeatedly produced a dramatic depressor response, albeit a transitory one. The blood pressure was finally controlled only with methyldopa intravenously on day 17 , followed by the oral form until discharge from hospital.

\section{COMMENT}

A list of various drugs known to antagonize the actions of adrenergic neuronal blocking agents is shown in the Table. To this list must be added phenylpropanolamine, a sympathomimetic drug which is one of the active ingredients of Ornade.

The postulated mechanisms whereby various compounds antagonize the actions of adrenergic neuronal blocking agents are: (1) by interference with the uptake of the neuronal blocking agent into the adrenergic neuron, where it must be concentrated to exert its effect; and (2) by preventing the

† Kindly supplied by Dr. Stanley T. Bloomfield, of Burroughs Wellcome and Co., Tuckahoe, N.Y. ‡ Kindly supplied by Dr. Robert L. Rowan, Schering Corporation,
Bloomfield, N.J. physiological re-uptake of released noradrenaline back into the adrenergic neuron. The latter may result in increased amounts of noradrenaline accumulating locally about the adrenergic neuron and receptor ${ }^{4}$ and may be an explanation for the depressor response noted with phentolamine hydrochloride in our patient.

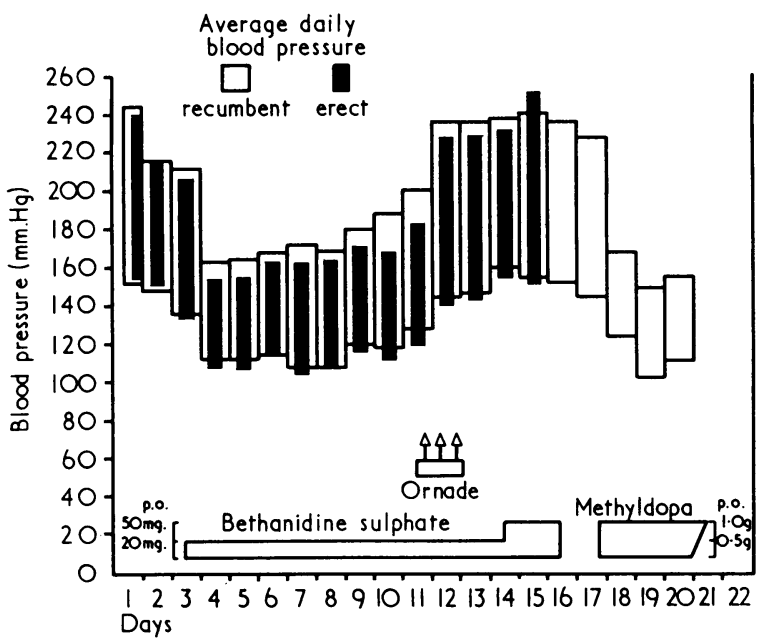

Average daily blood pressure during stay in hospital in recumbent and erect positions. Upper and lower boundaries of enclosed or black areas represent systolic and diastolic pressures respectively. Each black areas Oresentively. Each arrow ove $20 \mathrm{mg}$. daily was begun on day 3 , increased to $50 \mathrm{mg}$. daily on day 14 , and stopped on day 16 . Methyldopa $1 \mathrm{~g}$. by mouth was begun on day 17

Drugs Known to Antagonize the Actions of Adrenergic Neuronal Blocking Agents

\begin{tabular}{l|l}
\hline Sympathomimetic Amines & $\begin{array}{l}\text { Dexamphetamine sulphate } \\
\text { Ephedrine sulphate }\end{array}$ \\
Methylamphetamine hydrochloride
\end{tabular}

The reversal of the control of the blood pressure by such a preparation in our patient illustrates the dangers inherent in using such drugs when a hypertensive patient is receiving an adrenergic neuronal blocking agent.

JoHn R. Misage, M.D.,

Fellow in Medicine and Trainee supported by Clinical Pharmacology Training Grant, U.S.P.H.S. 5T1 H.E. 5467, whose funds supported this study.

Robert H. MCDONALD, JUN, M.D., Assistant Professor of Medicine, Departments of Medicine and Pharmacology, University of Pittsburgh, Pittsburgh, Pennsylvania.

\section{REFERENCES}

Leishman, A. W. D., Matthews, H. L., and Smith, A. J., Lancet, 1963, 1,112 .

2 Gulati, O. D., Dave, B. T., Gokhale, S. D., and Shah, K. M., Clinical Pharmacology and Therapeutics, 1966, 7, 510.

${ }^{3}$ Mitchell, J. R., Arias, L., and Oates, J. A., fournal of the American Medical Association, 1967, 202, 973.

4 Matsumoto, C., and Horita, A., Nature, 1962, 195, 1212. 